\title{
A linkage survey of 20 dominant retinitis pigmentosa families: frequencies of the nine known loci and evidence for further heterogeneity
}

\author{
Chris F Inglehearn, Emma E Tarttelin, Catherine Plant, Rachel E Peacock, \\ Mai Al-Maghtheh, Eranga Vithana, Alan C Bird, Shomi S Bhattacharya
}

\begin{abstract}
Autosomal dominant retinitis pigmentosa (ADRP) is caused by mutations in two known genes, rhodopsin and peripherin/ Rds, and seven loci identified only by linkage analysis. Rhodopsin and peripherin/ Rds have been estimated to account for $20-31 \%$ and less than $5 \%$ of ADRP, respectively. No estimate of frequency has previously been possible for the remaining loci, since these can only be implicated when families are large enough for linkage analysis. We have carried out such analyses on 20 unrelated pedigrees with 11 or more meioses. Frequency estimates based on such a small sample provide only broad approximations, while the above estimations are based on mutation detection in much larger clinic based patient series. However, when markers are informative, linkage analysis cannot fail to detect disease causation at a locus, whereas mutation detection techniques might miss some mutations. Also diagnosing dominant RP from a family history taken in a genetic clinic may not be reliable. It is therefore interesting that $10(50 \%)$ of the families tested have rhodopsin-RP, suggesting that, in large clearly dominant RP pedigrees, rhodopsin may account for $a$ higher proportion of disease than had previously been suspected. Four (20\%) map to chromosome 19q, implying that this is the second most common ADRP locus. One maps to chromosome $7 p$, one to $17 \mathrm{p}$, and one to $17 \mathrm{q}$, while none maps to 1 cen, peripherin/Rds, $8 \mathrm{q}$, or $7 \mathrm{q}$. Three give exclusion of all of these loci, showing that while the majority of dominant RP maps to the known loci, a small proportion derives from loci yet to be identified. (F Med Genet 1998;35:1-5)
\end{abstract}

Keywords: ADRP; retina; retinitis pigmentosa; retinal degeneration

Retinitis pigmentosa (RP) is an inherited retinal degeneration affecting approximately one in every $4000-5000$ people. ${ }^{12}$ It can be inherited as an $\mathrm{X}$ linked, dominant, recessive, or digenic disorder and at least 19 different genetic loci are now implicated in its causation. ${ }^{3}$ The dominant form (ADRP) accounted for $19 \%$ of all RP in a US survey ${ }^{2}$ and $22 \%$ in a UK survey. ${ }^{4}$ Within this category there is considerable locus heterogeneity. So far there are nine known loci for ADRP, on chromosomes 1cen, ${ }^{5}$ 3q21-24 (rhodopsin), ${ }^{6}$ 6p12 (Rds/peripherin), ${ }^{78}$ 7p13-15 (RP9), ${ }^{9}$ $7 q 31$ (RP10), ${ }^{10} 8 \mathrm{q} 11$ (RP1), ${ }^{11} 17 \mathrm{p}$ (RP13), ${ }^{12}$ 17q (RP16), ${ }^{13}$ and 19q (RP11). ${ }^{14}$

Mutations in the rhodopsin gene have been estimated to account for between 20 and $31 \%$ of ADRP, ${ }^{15-21}$ while peripherin/Rds mutations account for less than $5 \% .{ }^{21} 22$ The remaining seven ADRP loci were mapped by linkage analysis in large families. Some feeling for the frequencies of these loci can be gained by scanning the available publications. Further ADRP families have been reported as linked to $7 \mathrm{q}$, $17 p$, and $19 q$, suggesting that these might be commoner loci. ${ }^{23.26}$ However, frequency estimates based on published data would almost certainly be biased. Mutations in known genes can be detected in small pedigrees or even single patients, so these may be over-represented. Conversely as the number of such mutations reported goes up, their scientific priority goes down, so that they may no longer appear in published reports. Also, for linked loci, those discovered several years ago may have been tested more comprehensively in large families than those reported recently. Finally, it would be impossible to determine from such a survey whether any further ADRP loci remained to be found and what proportion of ADRP these loci accounted for.

The aim of this study is to estimate frequencies for the various forms of ADRP by reviewing previously published and new data generated on large ADRP pedigrees in this laboratory. This work has been carried out over the last seven years on ADRP DNA samples derived largely from patients in the Moorfields Eye Hospital Genetic Register and some other sources. Published data from this laboratory have included analyses of both large and small $A D R P$ pedigrees and of single $R P$ patients with a family history indicating dominant inherit- 
ance. However, in order to avoid bias owing to the factors described above, this study includes only those pedigrees for which there were sufficient DNA samples available for comprehensive linkage analysis (11 or more meioses). These criteria gave a set of 20 unrelated ADRP pedigrees, 17 of which have been assigned to the known ADRP loci and three of which exclude them.

\section{Materials and methods}

Over a period of around 15 years blood samples have been collected from 20 ADRP families with 11 or more meioses. These include 14 English, two Scottish, two Italian, one American, and one South African pedigrees. Where possible, all families were traced back several generations and no evidence of a common ancestor was found for any two of these families. Genomic DNA was prepared from these samples using a Nucleon II DNA extraction kit (Scotlab Bioscience). Microsatellite markers from known ADRP loci were then typed in the families by radioactive PCR amplification and size fractionation on $6 \%$ polyacrylamide denaturing gels. For most markers a standard cycling profile of 30-35 cycles at $94^{\circ} \mathrm{C}, 55^{\circ} \mathrm{C}$, and $72^{\circ} \mathrm{C}$ was used, with 30 seconds at each step. Products were labelled with P32 either by end labelling a primer or by incorporation of a small amount of labelled nucleotide. Lod scores were calculated from

A

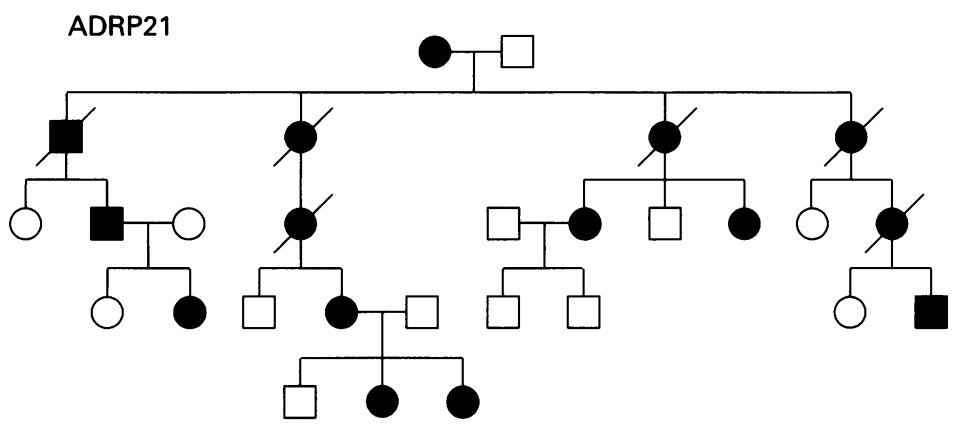

B

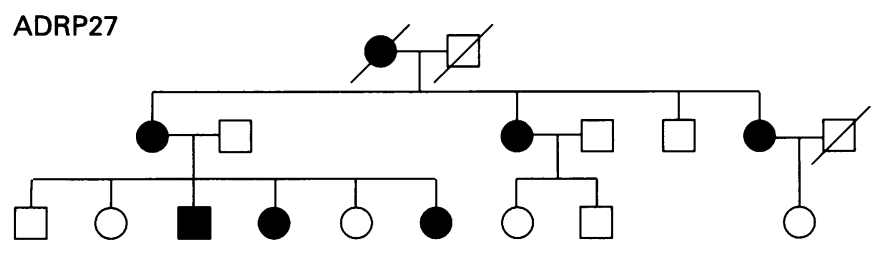

c

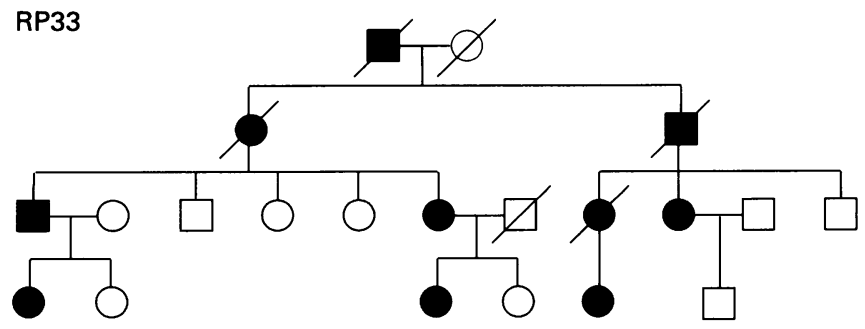

Figure 1 Families $A D R P 21(A), A D R P 27(B)$, and $R P 33(C)$, which are unlinked to any of the nine known rhodopsin-RP loci.
Table 1 Rhodopsin mutations identified in large ADRP families

\begin{tabular}{lllll}
\hline Codon & $\begin{array}{l}\text { Nucleotide } \\
\text { change }\end{array}$ & $\begin{array}{l}\text { Amino acid } \\
\text { change }\end{array}$ & $\begin{array}{l}\text { Lab family } \\
\text { name }\end{array}$ & Reference \\
\hline 23 & CCC-CAC & Pro-His & US RP & This study \\
135 & CGG-TGG & Arg-Trp & ADi-1 & This study \\
178 & TAC-TGC & Tyr-Cys & ADRP3 & 18 \\
178 & TAC-TGC & Tyr-Cys & ADRP16 & This study \\
190 & GAC-AAC & Asp-Asn & ADRP30 & 31 \\
255 & delATC & del Ile & ADRP14 & 32 \\
345 & GTG-ATG & Val-Met & RP2650 & This study \\
345 & GTG-ATG & Val-Met & ADRP6 & This study \\
347 & CCG-CTG Pro-Leu & ADRP1 & 18 \\
Lod score 4.82 at 0 cM with & ADRP 26 & This study \\
D3S1292 & & & \\
\hline
\end{tabular}

data files prepared on the LINKSYS (version 3.1) data management package then transferred to the LINKAGE (version 5.1) suite of programs. Linkage analysis was carried out both on a PC and on the Human Genome Mapping Project Resources Centre computing facility. Mutation screening of rhodopsin was carried out first by heteroduplex analysis ${ }^{27}$ and then by direct genomic sequencing of PCR amplified exons using a Pharmacia T7 sequencing kit.

\section{Results}

Of the 20 ADRP families tested, 10 mapped to the rhodopsin locus. In two of these the mutations were identified by direct screening of the rhodopsin gene by heteroduplex analysis, without initial linkage analysis. The remaining eight were first linked to the 3q21-24 region before subsequent rhodopsin mutation screening. Linkage mapping around the rhodopsin locus has in the past been difficult. The markers most commonly used to exclude it were $\mathrm{C} 17$ (D3S47), the Southern blot marker first linked to ADRP at 3q, ${ }^{6}$ and a microsatellite in intron 1 of the gene itself. ${ }^{28}$ However, D3S47 is now estimated to be some $18 \mathrm{cM}$ from rhodopsin ${ }^{29}$ while the intragenic microsatellite has a heterozygosity of only $33 \%$. By haplotype analysis in families linked to the $3 \mathrm{q}$ region, we have placed rhodopsin in the $5 \mathrm{cM}$ gap between markers D3S1292 and D3S1589 from the Genethon microsatellite map. ${ }^{30} \mathrm{D} 3 \mathrm{~S} 1292$ has a heterozygosity of $85 \%$, and gave a maximum lod score of 21.75 at $\theta=0.02$ with the ADRP phenotype in these families. It has therefore been used in this study as the marker of choice for the rhodopsin-RP locus.

The rhodopsin mutations found in nine of the $103 \mathrm{q}$ linked families are shown in table 1 . The finding of mutations in four of these families has been published previously, while the remaining six rhodopsin-RP families are described here for the first time. Each of the mutations identified had been described by this laboratory or by other researchers before this report. In two cases families shared the same mutation. Families RP2650 and RP1700 both have the codon 345 GTG-ATG (Val-Met) mutation, while families ADRP3 and ADRP16 both carry the codon 178 TAC-TGC (TyrCys) mutation. However, linked haplotypes for both D3S1292 and D3S1589 in each family were different. These data, together with the lack of genealogical evidence for a link between 
Table 2 Exclusion data in unlinked families

\begin{tabular}{|c|c|c|c|c|c|c|c|c|c|c|c|c|}
\hline \multirow[b]{2}{*}{ Locus } & \multirow[b]{2}{*}{$\begin{array}{l}\text { Markers } \\
A D R P 21\end{array}$} & \multicolumn{3}{|c|}{ Lod scores } & \multirow[b]{2}{*}{$\begin{array}{l}\text { Markers } \\
\text { RP33 }\end{array}$} & \multicolumn{3}{|c|}{ Lod scores } & \multirow[b]{2}{*}{$\begin{array}{l}\text { Markers } \\
\text { ADRP27 }\end{array}$} & \multicolumn{3}{|c|}{ Lod scores } \\
\hline & & 0.00 & 0.01 & 0.05 & & 0.00 & 0.01 & 0.05 & & 0.00 & 0.01 & 0.05 \\
\hline 1 cen/RP18 & D1S498 & $-\infty$ & -5.18 & -2.53 & D1S305 & $-\infty$ & -6.43 & -3.08 & D1S534 & $-\infty$ & -5.28 & -2.58 \\
\hline RHO & D3S1589 & -2.57 & -2.41 & -1.46 & ACPP & $-\infty$ & -4.31 & -2.20 & D3S 1292 & $-\infty$ & -3.45 & -1.51 \\
\hline RDS & PolyT & $-\infty$ & -4.13 & -2.09 & PolyT & $-\infty$ & -3.01 & -1.57 & PolyT & $-\infty$ & -1.10 & -0.48 \\
\hline 7p/RP9 & MS0006 & $-\infty$ & -2.56 & -0.94 & D7S460 & $-\infty$ & -5.19 & -2.51 & MS0006 & $-\infty$ & -4.02 & -2.04 \\
\hline $7 \mathrm{q} / \mathrm{RP} 10$ & D7S530 & $-\infty$ & -4.26 & -2.09 & D7S480 & $-\infty$ & -2.19 & -0.88 & D7S530 & $-\infty$ & -2.01 & -0.73 \\
\hline $8 \mathrm{~g} / \mathrm{RP1}$ & D8S285 & $-\infty$ & -2.80 & -1.37 & D8S166 & $-\infty$ & -6.45 & -3.17 & D8S166 & $-\infty$ & -6.36 & -3.64 \\
\hline $17 \mathrm{p} / \mathrm{RP} 13$ & D17S831 & $-\infty$ & -4.54 & -2.37 & D17S849 & $-\infty$ & -3.90 & -1.89 & D17S831 & $-\infty$ & -3.74 & -1.75 \\
\hline $17 \mathrm{~g} / \mathrm{RP} 17$ & D17S807 & $-\infty$ & -5.62 & -2.89 & D17S790 & $-\infty$ & -3.62 & -1.63 & $\mathrm{D} 17 \mathrm{~S} 807$ & $-x$ & -4.40 & -2.31 \\
\hline 19q/RP11 & D19S572 & -6.44 & -4.03 & -2.14 & D19S572 & -3.75 & -2.33 & -1.03 & D19S572 & -3.96 & -2.10 & -1.18 \\
\hline Xp22/RP15 & & & & & DXS1214 & $-\infty$ & -7.31 & -3.91 & & & & \\
\hline
\end{tabular}

Exclusion data for the known ADRP loci in the families shown in fig 1. In each case markers used are the closest informative systems, based on current published map refinements. Linkage analysis at the $19 \mathrm{q}(\mathrm{RP} 11)$ locus assumed a penetrance of 0.7 , while disease at other loci was assumed to be fully penetrant. For the most recent published locus refinements see the following references: RP9, ${ }^{37} \mathrm{RP} 10,{ }^{24} \mathrm{RP} 1,{ }^{38} \mathrm{RP} 13,{ }^{39} \mathrm{RP} 17,{ }^{13} \mathrm{RP} 11,{ }^{35} \mathrm{RP} 18 .{ }^{5}$ For the Rds locus, the 3 ' poly $\mathrm{T}$ polymorphism ${ }^{40}$ or D6S282 were used. For the rhodopsin locus as well as D3S1292 and D3S1589 (see results) the microsatellite ACPP, mapping $4 \mathrm{cM}$ from rhodopsin ${ }^{29}$ was used when necessary. At the RP9 locus we have identified a new poly-CA polymorphism known as MS0006, mapping centrally in the RP9 YAC contig, ${ }^{37}$ in a cosmid containing the marker D7S683. This highly informative microsatellite (heterozygosity 0.86 ) amplifies clearly and is now the polymorphism of choice for testing for RP9 linkage. Primers are ACTCCGCAGTAACATCATGG and CTCTAGTGTTTTCTAAAGCCAG which give a product of approximately $140-160$ bp in size.

these families, suggest that these mutations arose independently, though it remains possible that the families are distantly related. One other family, ADRP26, gave a lod score of 4.8 with D3S1292 but has failed to show a mutation in rhodopsin after being screened twice by both heteroduplex analysis and direct sequencing. It has previously been speculated that a second $3 \mathrm{q}$ locus existed close to RHO, though subsequent analysis of linked families appeared to exclude this. ${ }^{33}$ Such a locus could now be invoked to explain the results obtained in family ADRP26. However, given the apparent absence of any other such families among the many now tested world wide for linkage to rhodopsin, it seems more likely that the mutation is in an adjacent promoter sequence, or that it causes a PCR primer to fail to amplify the altered sequence, so that only the normal allele is seen on screening. A similar case has recently been described in the peripherin/Rds gene. ${ }^{34}$ Further analysis of this family is under way in an attempt to identify the mutation involved.

In a further four families, ADRP is linked to the RP11 locus on chromosome 19q. ADRP5, the family first linked to the locus, ${ }^{14}$ now gives a peak multipoint lod score of 9.3 with markers D19S572 and AFMc001yb1 at the locus. Families ADRP29, RP1907, and ADRP2 give two point lod scores of $3.19,3.04$, and 2.3 respectively with marker D19S572. These pedigrees show crossovers with all other ADRP loci and share a consistent "bimodal expressivity" phenotype. ${ }^{35}$ Haplotype analysis confirms that each of these families is unrelated to the others. One family in the set, known as

Table 3 Frequency estimates obtained in a genetic survey of 20 large $A D R P$ families

\begin{tabular}{lcc}
\hline Locus & $\begin{array}{l}\text { Families linked/ mutation } \\
\text { detected }\end{array}$ & Total \\
\hline 1cen (RP18) & 10 & \\
RHO & & $50 \%$ \\
RDS & 1 & $5 \%$ \\
7p13-15 (RP9) & & \\
8q11 (RP1) & 1 & $5 \%$ \\
7q31 (RP10) & 1 & $5 \%$ \\
17p13 (RP13) & 4 & $20 \%$ \\
17q22-24 (RP17) & 3 & $15 \%$ \\
19q13 (RP11) & & \\
Excluded & & \\
\hline
\end{tabular}

ADRP7, is the family in which an ADRP locus on chromosome $7 \mathrm{p}$ (RP9) was identified. ${ }^{9}$ No further families map to this locus. Another pedigree, assigned the number RPD8, is that in which a locus on $17 \mathrm{q}$ was discovered..$^{13}$ Finally, one pedigree, designated RP1729, maps to the RP13 locus on chromosome $17 p$, with a multipoint lod score of 5.1 between ADRP and markers AFMc024za5, D17S1529, and D17S831. ${ }^{36}$ No families in this set of 20 mapped to the 1 cen, peripherin/Rds, $7 q$, or $8 q$ loci.

In three families, known as ADRP21, ADRP27, and RP33, all of the nine known loci were excluded. These pedigrees are shown in fig 1 . In most cases the two point lod scores obtained in these families, shown in table 2 , exclude the entire $R P$ interval at each locus at a significance of $<-2$. Where they did not, other markers were typed and these data were analysed by multipoint linkage using the program Linkmap (data not shown), to extend the region excluded. Also, for family ADRP21, the rhodopsin poly-CA showed an intragenic crossover, but in the other families it proved uninformative. Families RP33 and ADRP21 have instances of male to male transmission, excluding $\mathrm{X}$ linked inheritance. However, since ADRP27 has no male to male inheritance, marker DXS1214, mapping to the RP6/RP15 locus, was typed, and a lod score for this marker in ADRP27 is given in table 2. This excludes linkage to the RP15 X linked dominant locus. ${ }^{41}$ The severity of the disease in female family members was considered to be inconsistent with $\mathrm{X}$ linked inheritance at the RP2 and RP3 loci. ${ }^{42}$ The results obtained were thus sufficient to exclude all loci in each family. Table 3 summarises the results described above.

\section{Discussion}

In this report we have described the completed analysis of $20 \mathrm{ADRP}$ families by both linkage analysis and mutation detection. In each family it has been possible either to assign the disease to a known locus or to exclude it from all such loci. This has provided an estimation of 
frequencies for the nine known ADRP loci and has also shown evidence for a further locus or loci.

The figure of $50 \%$ obtained for the frequency of rhodopsin-RP, assuming that the codon 178 and 345 mutations found in this sample arose independently, is higher than previous estimates. In spite of the small sample size this result is significantly different from published frequencies. Pooling the data from references 15 to 21 , a figure of 156 rhodopsin-RP cases out of 653 ADRP patients screened is obtained $(24 \%)$. With these data as a control, the observation of 10 out of 20 ADRP families with rhodopsin mutations is a significant deviation from the expected ratio $(\mathrm{p}<0.01)$. This may reflect a bias towards the fully penetrant form of RP associated with most of the rhodopsin mutations described to date, resulting from the selection of large families. There may also be sample bias in that, with the exception of the Italian families, these families are all of northern European origins. Alternatively this may imply that previous surveys have missed a proportion of mutations, since no mutation screening technique guarantees $100 \%$ success. ${ }^{43}$ This is further illustrated by the apparent absence of a mutation in ADRP26, a family clearly linked to the rhodopsin locus. It is therefore possible that rhodopsin, the gene first implicated in ADRP causation, may ultimately prove to be the most common site for mutations leading to dominant RP. If so, this would be an important result for diagnostic laboratories, which are currently faced with a complex task in attempting to provide a counselling service to RP sufferers.

Of the other ADRP loci only RP11 (19q) appears to account for a substantial proportion of the families studied. Obviously a figure of $20 \%$ is only an approximation, but the recent publication of a Japanese family also linked to $19 \mathrm{q}$ markers further underlines this locus as a significant cause of dominant RP world wide. For the remaining seven loci one or no families were identified as linked, suggesting that, in this sample of families at least, these were not a major cause of ADRP. Finally, three families or around $15 \%$ of the sample are excluded from linkage to any of the known loci. Therefore, while most cases of ADRP result from mutations in the known loci, a further locus or loci remain to be found.

In interpreting the data presented and reviewed in this study, it is necessary to recognise that a sample of 20 families is not large, and therefore these frequency estimates provide only a broad approximation of the true figures. Thus the loci which are represented in this survey by single families cannot be said to be significantly more frequent than those which were not found at all. However, the relative rarity of large ADRP pedigrees means that significantly better estimates are unlikely to become available until all dominant RP genes have been cloned. The families sampled will not reflect the sort of geographical variation in frequencies of the different forms of RP seen in other studies, ${ }^{44}$ but such variations are probably the result of a founder effect for single mutation events. The 20 families described here derive from a large outbred population and so should provide a good approximation of dominant RP frequencies world wide. For now, this study is at least a baseline for appreciating the relative clinical significance of each of the nine dominant RP loci described so far.

The results presented therefore imply that at least 10 loci are involved in causing ADRP. A further nine are implicated in recessive and $\mathrm{X}$ linked $R P$, while in addition there are at least four loci for Bardet-Biedl syndrome and seven for Usher syndrome, both of which involve RP and other defects. It is thus abundantly clear that $\mathrm{RP}$ is a relatively common phenotype associated with defects in many different genes, with each gene involved representing a component necessary for the maintenance of a normal retina. The identification and functional characterisation of each of these genes will undoubtedly improve our understanding of retinal function, which in turn may open up new routes to widely applicable therapies for the many different forms of RP. We gratefully acknowledge the Wellcome Trust (grant numbers
$035535 / \mathrm{Z} / 92,043006 / \mathrm{Z} / 94$, and $042375 / \mathrm{Z} / 94$ ), the Foundation Fighting Blindness USA, and the British Retinitis Pigmentosa Society for funding this research.

1 Boughman JA, Conneally PM, Nance WE. Population genetic studies of retinitis pigmentosa. $\mathrm{Am} \mathscr{f} \mathrm{Hum}$ Genet 1980;32:223-35.

2 Bunker CH, Berson EL, Bromley WC, Hayes RP, Roderick TH. Prevalence of retinitis pigmentosa in Maine. $A m \mathcal{F}$ Ophthalmol 1984;97:357-65.

3 Bird AC. Retinal photoreceptor dystrophies. Edward Jackson Memorial Lecture. Am f Ophthalmol 1995;119: Jackson

4 Bundey S, Crews SJ. A study of retinitis pigmentosa in the city of Birmingham. II. Clinical and genetic heterogeneity. f Med Genet 1984;21:421-8.

5 Xu SY, Schwartz M, Rosenburg T, Gal A. A ninth locus (RP18) for autosomal dominant retinitis pigmentosa maps in the pericentric region of chromosome 1. Hum Mol Genet 1996;5:1193-7.

6 McWilliam P, Farrar GJ, Kenna P, et al. Autosomal dominant retinitis pigmentosa (ADRP): localisation of an adRP gene to the long arm of chromosome 3. Genomics 1989;5:619-22.

7 Kajiwara K, Hahn LB, Mukai S, Travis GH, Berson EL, Dryja TP. Mutations in the human retinal degeneration slow gene in autosomal dominant retinitis pigmentosa. Nature 1991;354:480-3.

8 Farrar GJ, Kenna P, Jordan SA, et al. A three base pair deleFarrar GJ, Kenna P, Jordan SA, et al. A three base pair dele-
tion in the peripherin-RDS gene in one form of retinitis tion in the peripherin-RDS gene in

9 Inglehearn CF, Carter SA, Keen TJ, et al. A new locus for autosomal dominant retinitis pigmentosa on chromosome 7p. Nat Genet 1993;4:51-3.

10 Jordan SA, Farrar J, Kenna P, et al. Localisation of an autosomal dominant retinitis pigmentosa gene to chromosome 7q. Nat Genet 1993;4:54-7.

1 Blanton SH, Heckenlively JR, Cottingham AW, et al. Linkage mapping of autosomal dominant retinitis pigmentosa (RP1) to the pericentric region of human chromosom 8. Genomics 1991;11:857-69.

12 Greenberg J, Goliath R, Beighton P, Ramesar R. A new locus for autosomal dominant retinitis pigmentosa on the short arm of chromosome 17. Hum Mol Genet 1994;3:91518.

13 Bardien S, Ebenezer N, Greenberg J, et al. An eighth locus for autosomal dominant retinitis pigmentosa is linked to chromosome 17q. Hum Mol Genet 1995;4:1459-62.

$14 \mathrm{Al}$-Maghtheh $\mathrm{M}$, Inglehearn CF, Keen TJ, et al. Identification of a sixth locus for autosomal dominant retinitis . 351-4.

15 Sung $\mathrm{CH}$, Davenport CM, Hennessey JC, et al. Rhodopsin mutations in autosomal dominant retinitis pigmentosa. Proc Natl Acad Sci USA 1991;88:6481-5.

16 Dryja TP, Hahn LB, Cowley GS, McGee TL, Berson EL Mutation spectrum of the rhodopsin gene among patients with autosomal dominant retinitis pigmentosa. Proc Natl with autosomal dominant retinit

17 Sheffield VC, Fishman GA, Beck JS, Kimura AE, Stone EM. Identification of novel rhodopsin mutations associated with retinitis pigmentosa by GC-clamped denaturing with retinitis pigmentosa by GC-clamped denaturing
gradient gel electrophoresis. Am $\mathcal{F}$ Hum Genet 1991;49: gradient 
18 Inglehearn CF, Keen TJ, Bashir R, et al. A completed screen for mutations of the rhodopsin gene in a panel of patients with autosomal domir $1992 ; 1: 41-5$.

19 Bunge S, Wedeman H, David D, et al. Molecular analysis and genetic mapping of the rhodopsin gene in families with autosomal dominant retinitis pigmentosa. Genomics 1993 17:230-3.

20 Vaithnathan R, Berson EL, Dryja TP. Further screening of the rhodopsin gene in patients with autosomal dominan retinitis pigmentosa. Genomics 1994;12:461-3.

21 Souied EH, Rozet JM, Gerber S, et al. Screening for mutations within the rhodopsin, peripherin-RDS and ROM genes in autosomal dominant retinitis pigmentosa (ADRP)
in pedigrees from France. Invest Ophthalmol Vis Sci 1995;36(suppl):890.

22 Wells J, Wroblewski J, Keen TJ, et al. Mutations in the human retinal degeneration slow (RDS) gene can cause either retinitis pigmentosa or macular dystrophy. Nat Genet 1993;3:213-18.

23 Xu S, Nakazawa $M$, Tamai $M$, Gal A. Autosomal dominant retinitis pigmentosa locus on chromosome $19 q$ in retinitis pigmentosa locus on chromosome

24 McGuire RE, Gannon AM, Sullivan LS, Rodriguez JA Daiger SP. Evidence for a major gene (RP10) for autosoma dominant retinitis pigmentosa on chromosome $7 \mathrm{q}$ : linkage mapping in a second unrelated family. Hum Genet 1995;95 71-4

25 Millan JM, Martinez F, Vilela C, Beneyto M, Prieto F, Najera C. An autosomal dominant retinitis pigmentos family with close linkage to D7S480 on 7q. Hum Gene 1995;96:216-18.

26 Kojis TL, Heinzmann C, Flodman P, et al. Map refinemen of locus RP13 to human chromosome $17 \mathrm{p} 13.3$ in a second family with autosomal dominant retinitis pigmentosa. $A m \mathcal{F}$ Hum Genet 1996;58:347-55.

27 Keen TJ, Lester DH, Inglehearn CF, Curtis A, Bhattacharya SS. Rapid detection of single base mismatches as heteroduplexes on hydrolink gels. Trends Genet 1991;7:5.

28 Weber JL, May PE. Abundant class of human DNA polymorphisms which can be typed using the polymerase chain reaction. Am $\mathcal{f}$ Hum Genet 1989;44:388-96.

29 NIH/CEPH Collaborative Mapping Group. A comprehensive genetic linkage map of the human genome. Science sive genetic link

30 Gyapay G, Morissette J, Vignal A, et al. The 1993-94 Genethon human genetic linkage map. Nat Genet 1994;7:246 339 .
31 Keen TJ, Inglehearn CF, Lester DH, et al. Autosomal dominant retinitis pigmentosa: four new mutations in rhoics 1991;11:199-205.

32 Inglehearn CF, Bashir R, Lester DH, Jay M, Bird AC, Bhattacharya SS. A three basepair deletion in the rhodopsin gene in a family with autosomal dominant retinitis pigmentosa. Am $\mathcal{F}$ Hum Genet 1991;48:26-30.

33 Inglehearn CF, Farrar GJ, Denton M, Gal A, Humphries P Bhattacharya SS. Evidence against a second autosoma dominant retinitis pigmentosa locus close to rhodopsin on chromosome 3q. Am f Hum Genet 1993;53:536-7.

34 Fossarello M, Bertini C, Galantuomo MS, Cao A, Serra A Pirastu M. Deletion in the peripherin/RDS gene in two Sardinian families with autosomal dominant butterflyshaped dystrophy. Arch Ophthalmol 1996;114:448-56.

35 Al-Maghtheh M, Vithana E, Tarttelin E, et al. Evidence for a major retinitis pigmentosa locus on 19q13.4 (RP11) and association with a unique bimodal expressivity phenotype. Am ₹ Hum Genet 1996;59:864-71.

36 Tarttelin EE, Plant C, Weissenbach J, Bird AC, Bhattacharya SS, Inglehearn CF. A new family linked to the RP13 locus for autosomal dominant retinitis pigmentosa on dislocus for autosomal dominant retinitis

37 Keen TJ, Inglehearn CF, Green ED, et al. A YAC contig spanning the dominant retinitis pigmentosa locus (RP9) on chromosome 7p. Genomics 1995;28:383-8.

38 Sullivan LS, Blanton SH, Wagner MJ, Heckenlively JR Daiger SP. Fine structure linkage and physical mapping of the RP1 form of autosomal dominant retinitis pigmentosa. Invest Ophthalmol Vis Sci 1995;36(suppl):1044.

39 Goliath R, Shugart Y, Janssens P, et al. Fine localisation of the locus for autosomal dominant retinitis pigmentosa on chromosome 17p. Am $\mathcal{F}$ Hum Genet 1995;57:962-5.

40 Kumar-Singh R, Jordan SA, Farrar GJ, Humphries P. Poly (T/A) polymorphisms at the human retinal degeneration slow (RDS) locus. Nucleic Acids Res 1991;19:5800

41 McGuire RE, Sullivan LS, Blanton SH, Church MW, Heckenlively JR, Daiger SP. X-linked dominant cone-rod degeneration: linkage mapping of a new locus for retinitis pigmentosa (RP15) to Xp22.13-p22.11. Am ₹ Hum Genet pigmentosa $($ RP1

42 Bird AC. X-linked retinitis pigmentosa. Br $f$ Ophthalmol 1995;59:177-99.

43 Cotton RGH. Current methods of mutation detection. Mutat Res 1993;289:125-44.

44 Bird AC. Clinical investigation of retinitis pigmentosa. Aus NZ F Ophthalmol 1988;16:189-98. 